\title{
AMIDO A PARTIR DE BAMBU $\left(^{1}\right)$
}

ANísio AZZINI (2), Seção de Plantas Fibrosas, Instituto Agronômico.

\section{RESUMO}

Em colmos de bambu da espécie tida como Guadua flabellata, determinaram-se os teores de amido e das fraçōes fibrosa, parenquimatosa e solúvel em água. O comprimento e o diâmetro dos colmos processados foram também determinados. Os resultados mostraram que o teor médio de amido extraído foi $3,53 \%$ (base seca), representando cerca de $59 \%$ da fração solúvel em água e $32 \%$ do total de amido existente no colmo. Os teores méaios das frações fibrosa, parenquimatosa e solúvel em água foram, respectivamente, $61,76 \%, 23,05 \%$ e 15,18\%. Quanto às dimensōes do colmo, a espécie em estudo pode ser considerada de porte mediano, em comparação com as espécies mais difundidas em nossas condições.

\section{INTRODUÇÃO}

Em trabalho anterior (3), foi demonstrada a possibilidade de se extrair amido do colmo de bambu da espécie tida como Guadua flabellata. Em decorrência desse trabalho de pesquisa, foi possível solicitar junto ao Instituto Nacional da Propriedade Industrial (INPI) o pedido de patente ${ }^{\circ}{ }^{\circ} 8.104 .413$, relacionado com o processo de extração (1).

Quanto ao teor de amido no colmo de bambu, os dados encontrados na literatura são variáveis, dependendo da espécie e dos métodos de determinação. Deve-se salientar que os valores obtidos por HINO (5), 3,28\% a $9,40 \%$, AZZINI et alii (4), $29,66 \%$ a $41,07 \%$ e MENEZES

(1) Recebido para publicação a 7 de junho de 1982.

(2) Com bolsa de suplementação do CNPq. 
\& AZZINI (6), 30 a 45\%, referem-se à dosagem de amido no colmo, e não à quantidade de amido isolado.

O objetivo do presente estudo foi determinar o teor de amido isolado, bem como os teores dos materiais fibroso e parenquimatoso, resultantes do processamento do colmo de bambu.

\section{MATERIAL E MÉTODOS}

Foram utilizados três colmos de bambu da espécie tida como Guadua flabellata, provenientes da coleção existente no Centro Experimental de Campinas, Instituto Agronômico. As touceiras dessa espécie foram obtidas através de sementes, e não por via assexuada, como normalmente ocorre com bambu.

No laboratório, os colmos, após terem sido dimensionados quanto ao comprimento e diâmetro basal, foram reduzidos a cavacos com auxílio de um picador de bambu semi-industrial, e, os cavacos, desintegrados, na presença de água, em aparelho desintegrador tipo liquidificador de uso doméstico. Após a desintegração, obteve-se uma suspensão de amido em conjunto com outros resíduos, além de duas outras frações, uma fibrosa e outra parenquimatosa. Por decantação, o amido foi separado dos resíduos, seco e armazenado.

A desintegração dos cavacos é a etapa mais importante, pois é nela que os grânulos de amido são liberados das células parenquimatosas e arrastados pela água. O material desintegrado é recebido em uma peneira fina ou em pano, retendo-se, assim, as frações fibrosa e parenquimatosa. A água que atravessa a peneira, contendo amido e outros resíduos em suspensão, permanece em repouso, aproximadamente por doze horas. Para evitar o aparecimento de microrganismo, são adicionadas, nessa suspensão, algumas gotas de formol. Durante essa primeira decantação, o amido e os resíduos se precipitam, reduzindo-se o volume da suspensão, numa proporção de 8 para 1. Após, esse procedimento, a suspensão é submetida a uma segunda decantação de alguns minutos, separando assim os resíduos da suspensão de amido. A suspensão de amido sofre ainda uma terceira decantação mais ou menos lenta, obtendo-se assim o amido que pode ser seco, naturalmente, em condições do ambiente ou em estufa a $60^{\circ} \mathrm{C}$. As etapas desse processamento podem ser esquematizadas conforme mostra a figura 1.

\section{RESULTADOS E DISCUSSÃO}

O comprimento e o diâmetro do colmo em diferentes espécies de bambu, numa mesma condição edafoclimática, apresentam uma ampla variação, desde Dendrocalamus giganteus, apresentando colmos com $30 \mathrm{~m}$ de comprimento e $25 \mathrm{~cm}$ de diâmetro, até Arundinaria densifolia, 


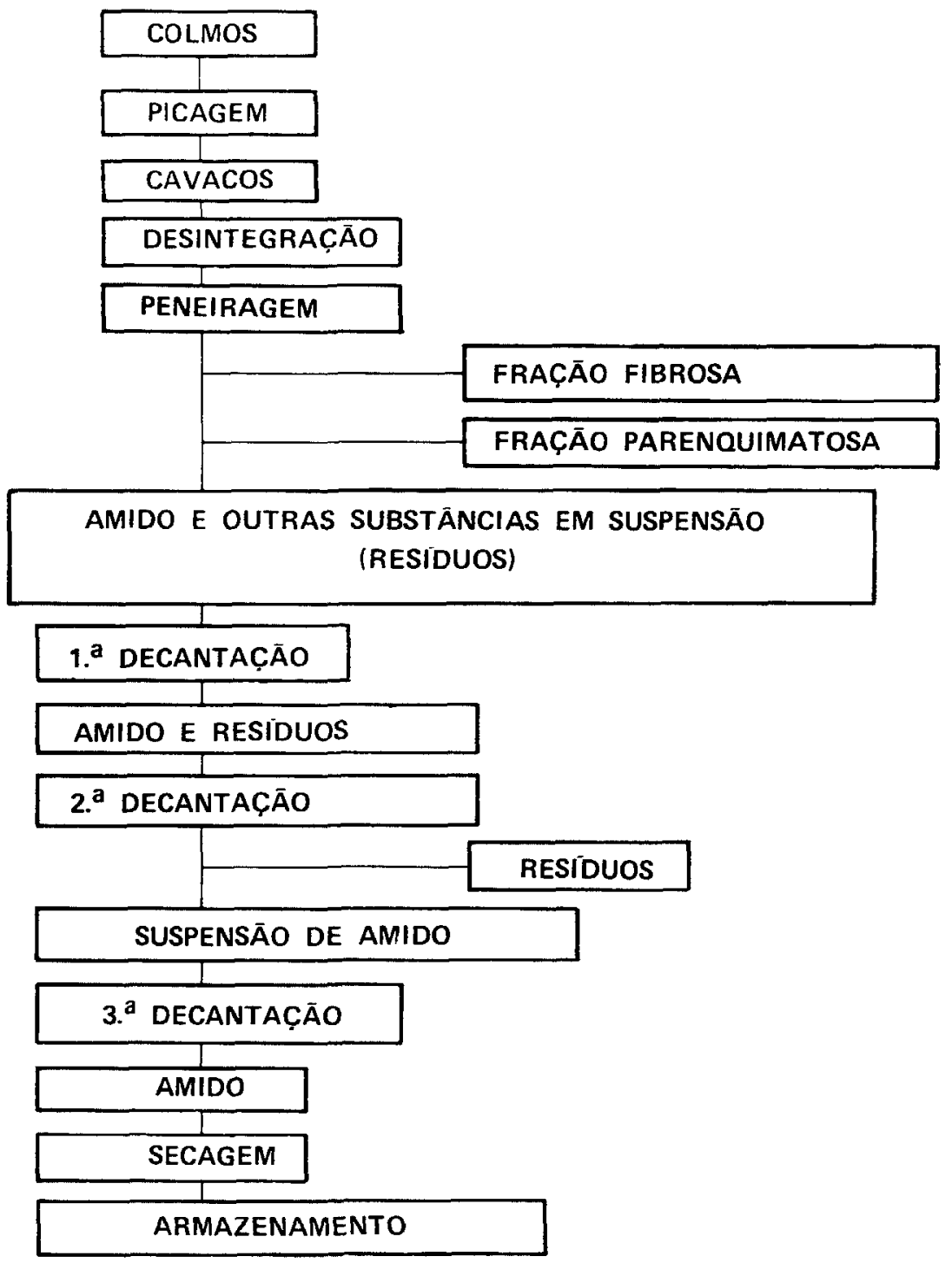

FIGURA 1 - Esquematização das etapas para extração de amido, a partir do colmo de bambu da espécie tida como Guadua flabellata. 
com colmos de $1 \mathrm{~m}$ de comprimento e $0,5 \mathrm{~cm}$ de diâmetro (2). A espécie em estudo apresenta colmos com dimensões médias de $9,76 \mathrm{~m}$ de comprimento e $5,6 \mathrm{~cm}$ de diâmetro (Quadro 1), podendo ser considerada de porte mediano, em comparação com as espécies D. giganteus, Bambusa tuldoides, B. vulgaris e B. vulgaris var. vittata, que apresentam maior valor econômico, como matéria-prima industrial, em nosso País.

QUADRO 1 - Comprimento e diâmetro basal dos colmos de bambu da espécie tida como Guadua flabellata. (Média de três colmos)

\begin{tabular}{lcc}
\hline Valores & Comprimento & Diâmetro basal \\
\hline & $\mathrm{m}$ & $\mathrm{cm}$ \\
Máximo & 10,60 & 6.20 \\
Médio & 9,76 & 5,60 \\
Mínimo & 8,30 & 4,80 \\
S & 1,27 & 0,75 \\
S $(\mathrm{x})$ & 0,73 & 0,43 \\
C.V. $(\%)$ & 13,04 & 13,36 \\
\hline
\end{tabular}

S: desvio-padrão; $\mathbf{S}(\mathrm{x})$ : erro-padrão da média; C.V.: coeficiente de variação.

No quadro 2, são apresentados os teores das fraçōes fibrosa, parenquimatosa e solúvel em água, após a desintegração dos cavacos. Esses valores diferem daqueles apresentados em trabalho anterior (3), provavelmente por diferenças na intensidade de desintegração dos cavacos.

QUADRO 2 - Teores das fraçōes fibrosa, parenquimatosa e solúvel em água no colmo de bambu da espécie tida como Guadua flabellata. (Médias de quinze repetições)

\begin{tabular}{lccc}
\hline & \multicolumn{3}{c}{ Fração } \\
\cline { 2 - 4 } & fibrosa & parenquimatosa & solúvel em água \\
& $\%$ & 0 & $\%$ \\
Máximo & 69,73 & 28,76 & 27,71 \\
Médio & 61,76 & 23,05 & 15,18 \\
Mínime & 43,68 & 17,59 & 10,36 \\
S & 6,62 & 3,58 & 4,04 \\
S(x) & 1,71 & 0,92 & 1,04 \\
C.V. (\%) & 10,72 & 15,54 & 26,62 \\
\hline
\end{tabular}

S: desvio-padrão; $\mathbf{S}(\mathrm{x})$ : erro-padrão da média; C.V.: coeficiente de variação. 
O teor médio de amido extraído a partir da fração solúvel em água foi $8,53 \%$. Esse teor representa cerca de $59,0 \%$ da fração solúvel em água e $32,0 \%$ do total de amido existente no colmo (Quadro 3).

QUADRO 3 - Teores de amido no colmo e na fração solúvel em água na espécie de bambu tida como Guadua flabellata. (Médias de quinze repetições)

\begin{tabular}{lcc}
\hline Valores & $\begin{array}{c}\text { Amido no } \\
\text { colmo }\end{array}$ & $\begin{array}{c}\text { Amido na fração } \\
\text { solúvel em água }\end{array}$ \\
\hline Máximo & $0 \%$ & $\%$ \\
Médio & 10,44 & $\mathbf{8 5 , 3 8}$ \\
Mínimo & $\mathbf{8 , 5 3}$ & $\mathbf{5 8 , 6 7}$ \\
S & 6,89 & 37,68 \\
S (x) & 0,81 & 11,84 \\
C.V. $(\%)$ & 0,21 & 3,05 \\
\hline
\end{tabular}

S: desvio-padrão; $\mathrm{S}(\mathrm{x})$ : erro-padrão da média; C.V.: coeficiente de variaçáo.

Esse rendimento de extração é relativamente baixo, considerando o teor de $26,92 \%$ de amido (3), determinado no colmo. Entretanto, esse rendimento pode ser otimizado, empregando-se um aparelho desintegrador mais eficiente, na presença de água com temperatura mais elevada. Além do amido, a fração fibrosa, já semiprocessada, pode ser facilmente convertida em celulose para papel, num processamento conjunto. Por outro lado, a fração parenquimatosa, por ser constituída de fragmentos celulares ricos ainda em amido, pode ser empregada na confecção de ração animal.

Os primeiros testes para caracterização do amido obtido demonstraram que ele apresenta características tecnológicas diferentes dos outros tipos de amido, principalmente com relação à perda e retenção de água.

\section{CONCLUSÕES}

a) O teor médio de amido extraído do colmo da espécie tida como G. flabellata foi $8,53 \%$ (base seca), representando cerca de $59 \%$ da fração solúvel em água e $32 \%$ do total de amido existente no colmo.

b) Quanto às dimensões do colmo, a espécie de bambu estudada pode ser considerada de porte mediano, em comparação com as demais espécies de ocorrência mais freqüente em nossas condições; 
c) A extração de amido, a partir da espécie em estudo, é um processamento muito simples, com a possibilidade de o amido obtido se tornar um subproduto da industrialização do bambu para celulose e papel, através da utilização da fração fibrosa que predomina no colmo. Para tanto, há necessidade de estudos posteriores, que caracterizem essa fração fibrosa como matéria-prima celulósica.

\section{SUMMARY}

\section{STARCH FROM BAMBOO CULM}

In bamboo culms of the species reported as Guadua flabellata were determined the contents of starch, fibrous fraction, parenchymatous fractions and water soluble fractions. The height and diameter of the bamboo culms were also determined. The results showed that the average content of extracted starch was $8.53 \%$ (over dry material). This content corresponds to about $59 \%$ of the fractions and $32 \%$ of the total starch present in the bamboo culm. The fibrous fractions and water soluble fractions were, respectively $61.76 \%$ and $23.05 \%$. Regarding te culm dimensions, this species can be considered as a middle sized culm.

\section{REFERENCIAS BIBLIOGRAFICAS}

1. AZZINI, A. Processo de extração de amido. Revista da Propriedade Industrial, Rio de Janeiro, (ago.):33, 1981.

2. ; CIARAMELIO, D.; NAGAI, V. Celulose de bambu. In: CONVENÇĀO ANUAL DA ASSOCTAC̆ÃO TÉCNICA BRASILEIRA DE CELULOSE E PAPEL, 5., São Paulo. Anais. 1972. p.195-201.

3. — SALGADO, A. L. B.; TEIXEIRA, J. P. F.; MORAES, R. M. Obtenção de amido a partir do colmo de bambu. Bragartia, Campinas, 40:211-216, 1981. (Nota, 7)

4. — SILVA, M. T. R.; TEIXEIRA, J. P. F.; MORAES, R. M. Teor de carboidrato em colmos de Bambusa vulgaris Schrad. Bragantia, Campinas, 33:XV-XVII, 1979. (Nota, 4)

5. HINO, I. Icones Iungorum bambusicolorum japonicorum. Yamagutiensi. Facultate Agriculturae in Universitate., 1961. 336p. il.

6. MENEZES, T. J. B. \& AZZINI, A. O bambu, uma nova matéria-prima para a produção de etanol. Boletim do Instituto de Tecnologia de Alimentos, Campinas, 18:145-154, 1981. 